\title{
WHAT MOTIVATES COMMUNITY HEALTH VOLUNTEERS IN MECANHELAS DISTRICT, MOZAMBIQUE? REPORT FROM A QUALITATIVE STUDY
}

\author{
"A.S. MUULA, J. HOFMAN, 'MARGARET CUMBERLAND \\ Department of Community Health, University of Malawi College of Medicine, Malawi and 'CORD \\ Training for Health Project, Mecanhelas, Mozambique
}

\begin{abstract}
SUMMARY
Community health volunteers (CHVs) are an important arm of the health care delivery system in Mecanhelas District, Mozambique. The CHVs receive limited incentives from the project's external donors. We report on a qualitative study conducted in 2002 to determine issues that influence motivation of the CHVs. Respondents reported desire to have more incentives other than a bar of soap each month and food and accommodation at workshops. Some of the responses drew from experience in neighbouring Malawi where several of the volunteers had been refugees during the Mozambique civil war. We suggest that incentives are an important aspect of volunteer work in the present setting. However an incentives system must be culturally acceptable, affordable and should not negatively affect the sustainability of a health program. The decision as to which incentives to give should be a consensus among the community, the volunteers and the project staff.
\end{abstract}

Keywords: community health volunteers, incentives, Mecanhelas, Niassa

\section{INTRODUCTION}

Mozambique is among the poorest countries in the world. The maternal mortality ratio is estimated as about 1,500 deaths per 100,000 live births, the average life expectancy at birth at about 46 years and public health care facilities are generally poorly staffed and under-stocked ${ }^{1.2}$. Mecanhelas is a district in Niassa province, the Mozambique's largest Province which covers $16 \%$ of the country. The province has 756,000 inhabitants of which $77 \%$ are rural dwellers. The local languages distribution are as follows; $55 \%$ Macua, $37 \%$ Yao and $8 \%$ Nyanja ${ }^{3}$. The district has 8 health centers with a total of 72 admission beds among them and 13 health posts. Twelve of the 13 health posts are run by community volunteers or denominational institutions. The health posts are manned by Agentes Pollivalentes Elementaires (APEs) who receive residential training of between 6 to 13 weeks or health advisors with a much shorter and less structured training. There is no district hospital and major operative procedures such as Caesarian sections are only available at Cuamba Rural Hospital, 80 kilometers away.

The district is divided into 4 localities; Insaca, Chissaua, Chamba and Chiuta. Each locality has a government-appointed leader (Presidente da Localidade and a traditional leader (Regulo). The locality is also divided into traditional administrative structures called Ndunas (under the leadership of an Nduna). Ndunas are further subdivided into Chefes, which are headed by a 'Chefe'. The number of households under a chefe varies between 30 and $150^{4}$.

Since the end of the civil war between RENAMO and FRELIMO in 1992, Mozambique has been recipient of increased donor aid in the health sector 5.6. Despite the efforts by the government of Mozambique to improve access to health care facilities and services, many Mozambicans have limited access to modern health care facilities. The province of Niassa, and especially Mecanhelas District are among the least developed in Mozambqique.

In order to improve availability and accessibility of health care but also encourage disease preventative efforts, a 'Training for Health' project was initiated by Christian Outreach-Relief and Development (CORD-UK) in 1999. In this project, selected community members in Jassamire and Nampande, were trained and they in turn provided

\footnotetext{
"Author for correspondence
} 
health education and curative health care to their community as volunteers.

We report the findings from a qualitative study conducted to determine issues that influence community health volunteers (CHVs) to work in their communities in Mecanhelas District, Mozambique.

\section{MATERIALS AND METHODS}

A qualitative study utilizing 5 sessions of focus group discussions (FGDs) was conducted in 2002 in the Mecanhelas District, Niassa Province in north-west Mozambique. We determined to identify issues relating to community health volunteers' motivation and what could be done to motivate them further. Twenty-one trained traditional birth attendants (TBAs), and 8 health advisors and 22 village health committee members in Nampande and Jassamire were involved. The interviews were conducted in Portuguese, Nyanja and Macua. Questions and answers were translated into Nyanja or English where appropriate (the Principal author's mother tongue is Nyanja). Analysis was done based on themes and respondents' views reported verbatim.

\section{RESULTS}

Community health volunteers in the areas of Nampande and Jassamire, Mecanhelas, Mozambique were being provided with a bar of soap and lunch when they met at least once every month. There were no monetary incentives. Other issues identified were as follows:

\section{Hope for the future}

Participants indicated that at the start of the project (Training for Health), they were informed clearly that they would not be remunerated. One responded said,

'When the project was started, they clearly told us that we were not going to be paid. But when one tells you something, you don't always believe that the situation will be like that forever. Things change. Now we know that they actually meant what they said. We're not being paid just like they said at the beginning.'

Another participant said, "When a child is born, it just doesn't start walking the same day. It begins with crawling. We understand that this project will grow. And we may then start getting paid.'

Participants were also encouraged by a better future for their children. 'In the past this community was backward and our children were dying. Now we can arrest some of the causes of deaths and illness. We will continue until these problems are virtually removed. We are making a contribution to our own community. Why should we stop? said another respondent.

It was also reported by some of the volunteers that their initial understanding was that the communities would provide incentives for them. 'Our understanding was that by and by, our communities would be contributing in cash or kind for our compensation. The ideas had been discussed by the chefes. But the community refused to contribute. The Chefes then said, "The community did not employ you. You're volunteers."

\section{Incentives are important}

All discussion groups and individual interviews indicated that incentives were crucial if the project was going to rely on community volunteers. 'One male volunteer dropped out because of pressure from his wife. She wondered why he was still working for no pay. So the man was given a choice whether to continue being a volunteer or else have the marriage terminated'. Respondents indicated that although monetary incentives could be considered, other non-monetary incentives were acceptable.

A participant remarked; 'We are not asking for money as such. But there must be some identification. We're talking about some distinguishing feature between a community health volunteer and an ordinary member of the community. Something like a T-Shirt or a badge.' Participants who had either travelled or heard about the incentives practice in Malawi indicated that monetary allowances could also be considered. "We have heard that TBAs and other health volunteers receive an allowance when they attend seminars in Malawi'. It was also reported that exchange visits to other areas of the district and even in other countries could be conducted to motivate the volunteer. 'Our training on HIV/AIDS is just on the surface. We hear from people that Malawi is far ahead. We should visit Malawi.'

\section{The future of incentives}

It was reported also that realization of the impact of the 'Health for Training' Project was likely to be hampered by lack of enthusiasm by volunteers. Participants indicated less preference that the incentives should be provided by their own community as opposed to external donors. Some respondents reported that not all community members appreciated the role of volunteers. "Some people 
don't even think about us once we have assisted them in childbirth. Others are however, understanding. They thank us in kind,' said a TBA at Jassimire. Participants also indicated that their communities seemed not to belicve that the volunteers were indeed working without pay. The community is wondering; "Who can be employed without being paid. Nada (no).'

One of the areas of misunderstanding was the monthly meetings that volunteers had. 'Because we do come to the training centre once a month, the community tends to think that is the pay day. But they don't understand that this is a day when we submit our monthly reports. Nothing more' said a volunteer at Jassimre. When it was suggested to the volunteers that the communities they serve be encouraged to support them with incentives, such option was viewed less favourably. Some respondents indicated that the community members were themselves lacking material resources. It was also indicated that collecting contribution regularly exhausts the good will (fatigue). 'And in any case,' said one respondent, 'if they start giving us incentives they will say, "Who are you? We feed and clothe you.' The wider indication was, however, that external donors be responsible for material incentives to CHVs.

\section{DISCUSSION}

Community health volunteer groups are an important aspect of health care services delivery in Mecanhelas District, Mozambique. Volunteers receive direct incentives mostly as a bar of soap every month and food and accommodation at workshops. However, there seems to be a general feeling among the CHVs that probably more, and other types of incentives other than those currently available, be provided. CHVs indicated that their own communities were unlikely to be sources of such incentives. Voluntarism has been around since antiquity. Individuals have provided themselves for service to humankind even in situations where potentially personal harm was higher and compensated only by community benefit ${ }^{7}$. There is however a general understanding that volunteer and cooperative behaviour is likely to be sustained when there is either direct or indirect reciprocity in which benevolence of one individual increases chances of receiving help or recognition directly or indirectly from the other ${ }^{8-9}$. Respondents in the present study had higher expectations from donors probably through their experience of the situation in neighbouring Malawi. Half of the population of Mecanhelas had fled to Malawi during the Mozambique civil war, resulting in the population of the district being 48,000 in 1989 and 119,848 in 1997 when repatriation had occurred ${ }^{10.11}$.

One interesting feature regarding voluntarism is that it is more likely to develop if one is of service to her or his own community or species, even among animals 12,13 . It is generally agreed that workforce planning needs to give due consideration to working conditions, incentives and rewards for all health workers, thus including CHVs ${ }^{14}$. While many of our respondents indicated some kind of material incentives, it is important to realize also that volunteers can be offered non-material and non-monetary incentives. In a study of nonsalaried clerkship teaching staff in the United States, educational opportunities, travel and meeting registration re-imbursement and personal satisfaction were ranked higher than payment and gifts $^{15}$. Of course the difference between this group and our respondents being that while in the US study there were practicing specialist doctors with a steady income, our respondents were mostly subsistence farmers. The needs and aspirations of the two groups may therefore be different.

We believe that incentives to volunteers should be decided through dialogue among the community, the project (paid) staff and the CHVs themselves. The incentives must be culturally acceptable, affordable but also not negatively affect sustainability of the project ${ }^{1+15}$

\section{ACKNOWLEDGEMENTS}

We are deeply indebted to the following, Americo Dos Santos N'cuha and Arcangelo Amussala, District Director of Health and Chief of Community Health Department respectively, Mecanhelas District. The invaluable support by the Christian Outreach-Relief and Development (CORD) Training for Health Team is appreciated. This study would not have materialized without the generosity of the community health volunteers with their time. Funding and logistical support of the exercise was by Foundation for Community Development through CORD, to whom we are very grateful.

\section{REFERENCES}

1. Government of Mozambique and United Nations Population Fund. Strategies for the Reduction of Maternal and Neonatal Morbidity and Mortality Year 2000. Ministry of Health, Department of Community Health, 2002

2. Government of Mozambique and United $\mathrm{Na}$ tions Population Fund. Maternal and Perinatal Mortality Reduction. National Opera- 
tional Plan 2000-2005. Ministry of Health, National Health Directorate, Community Health Department, 2002

3. Republic of Mozambique. Government of Niassa Province. Reviewing Hope. Lichinga, 1999

4. CORD. Training for Health. Interim Report 1999-March 2000. Mecanhelas District, Niassa Province, Mozambique

5. Pavignani E, Durau JR. Managing external resources in Mozambique: building new aid relationships on shifting sands? Health Policy and Planning 1999; 14(3): 243-253

6. UNDP. Mechanisms for coordinating and integrating external Assistance. Experience of the Health Sector in Mozambique. United Nations Development Program, 1996

7. Seelig BJ, Dobelle WH. Altruism and the volunteer; psychological benefits from participating as a research subject. ASATO 2001; 47: 35

8. Axelord R, Halmiton WD. The evolution of cooperation. Science 1981, 2111:1390-1396

9. Sigmund K, Nowak MA. Tides of tolerance. Nature 2001; 414: 403-405

10. Health Situation Analysis. Report on Focus Group Discussion. PVO Support II Project.
Niassa Province Child Survival and Community Health Project. Medical Care Development International, 1998

11. Health situation Analaysis. Districts of Cuamba, Muaa, Mecanhelas and Metarica. Niassa Province. PVO Support II Project. Niassa Province Child Survival and Community Health Project. Medical Care Development International, 1998

12. Dawkins R. The selfish gene. Oxford. Oxford University Press, 1990

13. Agrawal AF. Kin recognition and evolution of altruism. Proc Roy Soc Lond 2001; 268: 1099. 1104

14. Jones R. Declining altruism in medicine. $B r i$ Med J 2002: 324: 624-625

15. Kumar A, Kallen DJ, Mathew T. Volunteer faculty: what rewards or incentives do they prefer? Teach Learn Med 2002; 14(2): 119 123

16. Coutright P, Biggs-Jarrell B. Village health volunteers: key issues facing agencies in Malawi. Malawi Med J 1992; 8: 67-69

17. Reid M, Coutright P. How do we sustain village health volunteers. Malawi Med J 1993; 9: 7.9 